\title{
Use of the progestin challenge test in diagnosing amenorrhea: the time has come to say goodbye.
}

\author{
William D. Schlaff \\ Thomas Jefferson University \\ Charles C. Coddington \\ Carolinas Medical Center, Atrium Health
}

Follow this and additional works at: https://jdc.jefferson.edu/obgynfp

Part of the Obstetrics and Gynecology Commons

\section{Let us know how access to this document benefits you}

\section{Recommended Citation}

Schlaff, William D. and Coddington, Charles C., "Use of the progestin challenge test in diagnosing amenorrhea: the time has come to say goodbye." (2020). Department of Obstetrics and Gynecology Faculty Papers. Paper 60.

https://jdc.jefferson.edu/obgynfp/60

This Article is brought to you for free and open access by the Jefferson Digital Commons. The Jefferson Digital Commons is a service of Thomas Jefferson University's Center for Teaching and Learning (CTL). The Commons is a showcase for Jefferson books and journals, peer-reviewed scholarly publications, unique historical collections from the University archives, and teaching tools. The Jefferson Digital Commons allows researchers and interested readers anywhere in the world to learn about and keep up to date with Jefferson scholarship. This article has been accepted for inclusion in Department of Obstetrics and Gynecology Faculty Papers by an authorized administrator of the Jefferson Digital Commons. For more information, please contact: JeffersonDigitalCommons@jefferson.edu. 
Use of the Progestin Challenge Test in Diagnosing Amenorrhea: The Time Has Come to Say Goodbye

William D. Schlaff, M.D. ${ }^{a}$ and Charles C. Coddington, M.D. ${ }^{b}$

aDepartment of Obstetrics and Gynecology, Sidney Kimmel Medical College, Thomas Jefferson University, Philadelphia, PA 19107

${ }^{b}$ Department of Obstetrics and Gynecology, Carolinas Medical Center, Atrium Health, Charlotte, NC

The evaluation of amenorrhea, whether primary or secondary, has long been inconsistent, confused, or both for many practitioners. As we consider diagnostic paradigms commonly pursued today, it is useful to consider the genesis as well as the longstanding applicability and value of the commonly employed progestin challenge test. To our knowledge, the progestin challenge test became a widely used and standard diagnostic test following publication of a textbook, Clinical Gynecologic Endocrinology and Infertility, by Drs. Speroff, Glass, and Kase in 1973 (1). This team of reproductive endocrinologists made a profound contribution to clinicians by describing an organized, "compartmentalized" approach to the diagnosis of amenorrhea. One of the key components of this diagnostic cascade was the administration of a progestational agent which would be expected to induce secretory transition of an estrogenized endometrium and produce withdrawal vaginal bleeding in women whose uterovaginal anatomy was normal and intact. The presence of bleeding was (and continues to be) indicative of chronic, estrogenized anovulation. Conversely, the absence of bleeding in nonpregnant patients was to be interpreted as reflective of hypoestrogenism, an abnormal or congenitally absent outflow tract, or (left unsaid) failure of the patient to take the medication.

As we reflect on the clinical context in which the progestin challenge test became the standard approach in the evaluation of amenorrhea, we should be mindful of the diagnostic tools available to our clinical leaders in the late 1960s and 1970s. Hormonal assays were much less sensitive and clinical laboratories performed them far less frequently compared to what we now expect. To think that a folliclestimulating hormone or estradiol value would be back within 90 minutes of a patient leaving the office would not have crossed the mind of any physician. Clinical use of ultrasound was barely beginning, and the notion that a real time ultrasound could be performed (never mind interpreted with confidence about its accuracy) would have been wishful thinking, if not frank fantasy. In this context, we can understand the relative simplicity of the patient's trek to her local pharmacy where she presumably could fill her prescription for a progestin without computerized validation of her prescription plan, determination of co-pay, and documentation of the universe of adverse effects that could result from the medication. Further, after taking the medication for 5 days, waiting 2 to 7 days for bleeding to occur (or not), and then making an appointment for a follow-up consultation (without needing a referral or additional co-pay), she would have a good idea of what needed to be done either diagnostically or therapeutically - all within 3 to 4 weeks. If the patient did not have bleeding (for the moment ignoring the diagnostic dilemma of "just a little spotting"), the next recommendation would be to treat with estrogen for approximately 21 days, adding progestin during the last 5 , and awaiting bleeding to determine if functional endometrium was present. The absence of withdrawal bleeding would then 
trigger further testing which would have to be deferred for an additional 2 to 3 weeks to escape the impact of exogenous hormones on the validity of gonadotropin measurement.

This diagnostic approach continues to be in wide, and arguably standard use today as well. It is timely to consider more contemporary options. Our ability to take an accurate history or perform an examination to help direct our diagnostic approach is no better today than it was then; hopefully it is as good. On the other hand, we can certainly reach the initial diagnostic stage much more expeditiously with a straightforward transvaginal ultrasound following a history and physical exam. Most clinicians, not to mention their advance practice providers or ultrasonographers, can easily determine the endometrial thickness and pattern in a matter of minutes. In most cases, this will allow a rapid and highly accurate assessment of estrogenization. In more complex cases in which an outflow tract abnormality or intrauterine synechiae are suspected, the clinician can often make a tentative if not firm diagnosis by performing the ultrasound her/himself. If the degree of estrogenization is minimal or unclear, gonadotropin and/or other diagnostic hormonal tests can be ordered at the time of the initial visit. Conversely, administering a progestin as an initial diagnostic step will not only produce more inconvenience, it will necessitate a waiting period of at least 10 to 14 days for results. If there is no bleeding or the initial results are inconclusive, diagnosis will be delayed a further two to six weeks for lab tests or administration of estrogen plus progestin. Clearly there is a cost for a limited ultrasound, but there is also a real cost of medications, inconvenience, repeated office visits, and unnecessary delays in diagnosis if one elects to perform a progestin challenge test.

To be fair, we respect that the description and interpretation of the progestin challenge test have evolved in ensuing editions of Clinical Gynecologic Endocrinology and Infertility. Nevertheless, we feel that it is time to largely abandon this approach as an initial diagnostic tool in the evaluation of amenorrhea. We propose that a directed history and examination, limited ultrasound, and focused laboratory evaluation at the initial visit should be the standard approach.

In the Preface to the 1st edition of Clinical Gynecologic Endocrinology and Infertility [and quoted in the Preface to the 7th edition (2)], the authors acknowledged that physicians often feel uncomfortable when confronted by endocrine problems. They attributed this unease to challenges in knowledge and approach, both of which they suggested have been improved by the explosion of scientific information to which they themselves have contributed in a profound way. The authors cautioned that physicians should avoid attempting to overcome their difficulty "by mastering a ritualistic series of steps to follow for each presenting symptom" (2) and encouraged us to avoid rigidity in our approach to individual patients. Certainly, Dr. Speroff accomplished this educational goal in each of the eight editions of this iconic text, the last two of which he published with our esteemed colleague and friend, Dr. Marc Fritz in 2013. Indeed, his extraordinary contributions were recognized by the updated title of the recently published 9th edition of the text, now called Speroff's Clinical Gynecologic Endocrinology and Infertility, authored by Drs. Hugh Taylor, Lubna Paul, and Emre Seli (3). In proposing that it is time to say goodbye to the progestin challenge test as a diagnostic tool, we do so with profound admiration and respect for Dr. Speroff. Indeed, if there were a Mount Rushmore of reproductive endocrinologists he would no doubt be one of the faces at which we would gaze. We offer our suggestion in the same spirit of embracing change based on increased scientific information and technology, unburdened by ritualistic devotion. 
References:

1. Speroff L, Glass RH, Kase NG. Clinical Gynecologic Endocrinology and Infertility. Williams \& Wilkins, Baltimore, MD, 1973

2. Speroff L, Fritz MA. Clinical Gynecologic Endocrinology and Infertility. Seventh Edition, Lippincott Williams \& Wilkins, Baltimore, MD, 2005

3. Speroff L, Fritz MA. Clinical Gynecologic Endocrinology and Infertility. Seventh Edition, Lippincott Williams \& Wilkins, Baltimore, MD, 2005, page vi 